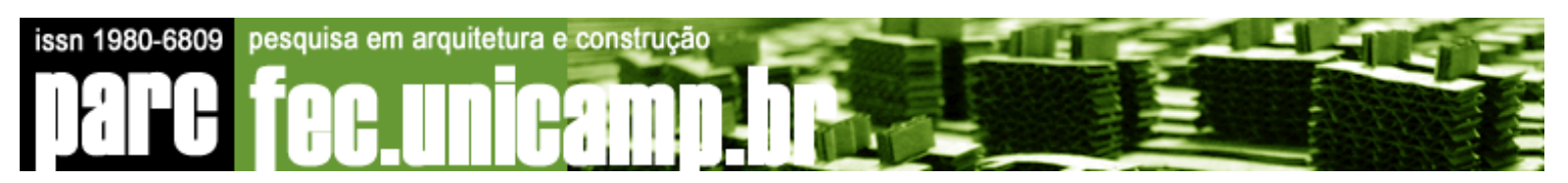

\title{
Comportamento Térmico de Cobertura Verde Utilizando a Grama Brachiaria Humidicola na Cidade de São Carlos, SP
}

\section{Thermal Performance of Green Roof Using the Brachiaria Humidicola Grass in the City of São Carlos, SP}

NIXON CÉSAR DE ANDRADE (1); MAURÍCIO RORIZ (2)

(1) deandraden@bol.com.br (2) m.roriz@terra.com.br

(1) Engenheiro Civil pela Universidade Federal de São Carlos, Mestre em Construção Civil pela Universidade Federal de São Carlos, Doutorando do Programa de Pós-Graduação em Engenharia Civil da Faculdade de Engenharia Civil, Arquitetura e Urbanismo da Universidade Estadual de Campinas.

(2) Professor do Programa de Pós-Graduação em Construção Civil da Universidade Federal de São Carlos, Arquiteto e Urbanista pela Universidade Católica de Goiás, Mestre em Arquitetura pela Escola de Engenharia de São Carlos da Universidade de São Paulo, Doutor em Arquitetura pela Faculdade de Arquitetura e Urbanismo da Universidade de São Paulo.

\section{RESUMO}

O objetivo deste trabalho é analisar o comportamento térmico de uma cobertura ajardinada com a grama Braquiária (Brachiaria humidicola), que atinge 1m de altura, comparando-a com a de uma cobertura tradicional (laje exposta). Considerando-se os dados obtidos por meio de monitoramentos com aparelhos registradores de temperaturas e umidades relativas, em diferentes épocas do ano, analisou-se o comportamento térmico das coberturas tradicional e verde. Foram medidas as temperaturas do ar no interior e no exterior das células-teste e as superficiais internas de ambas as células. Os resultados indicam que, submetida ao clima local, a cobertura ajardinada apresenta ótimo desempenho, particularmente por amortecer as temperaturas das superfícies externas e internas da cobertura. Nessa mesma célula-teste realizou-se recentemente uma pesquisa similar, mas que utilizou a grama Esmeralda (Zoysia japonica), uma vegetação rasteira. Comparando-se os resultados dos monitoramentos realizados, nos períodos de frio e calor, foram detectadas diferenças entre os comportamentos térmicos das duas gramas.

Palavras-chave: Coberturas Verdes, Estratégias Passivas de Condicionamento Térmico, Arquitetura Bioclimática. 


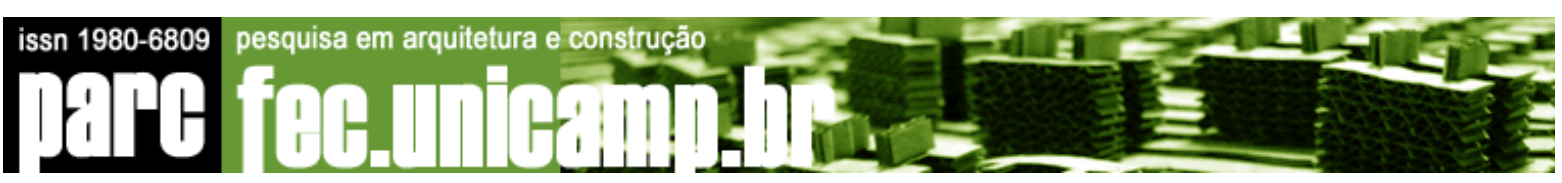

ABSTRACT

This work aims to analyze the thermal behavior of a green roof with the Braquiária grass (Brachiaria humidicola), that reaches $1 \mathrm{~m}$ height, comparing it with a traditional roof (exposed concrete slab). Considering temperature and relative humidity data obtained through field measurements in different months, the thermal performance of the green and traditional roofs was analyzed. The inside and outside temperatures, and inside superficial of two test-cells were analyzed. The results indicate that, submitted to the local climate, the green roof presents optimum performance, particularly for decreasing the temperatures of external and internal roof surfaces. In the same test-cell it was recently realized a similar research, which used the Esmeralda grass (Zoysia japonica), a short vegetation. Comparing the measurement results for cold and hot periods, it was noticed differences between the thermal performance of the two grasses.

Keywords: Green Roofs, Passive Strategies of Thermal Conditioning, Bioclimatic Architecture. 


\section{Comportamento Térmico de Cobertura Verde Utilizando a Grama Brachiaria Humidicola na Cidade de São Carlos, SP}

\section{INTRODUÇÃO}

A arquitetura é também conseqüência das diferenças climáticas de regiões, precisando priorizar esta condição para resolver os problemas quanto ao conforto térmico da habitação. Nesse sentido, diversas soluções construtivas são utilizadas por engenheiros e arquitetos, mas deve-se entender que a cobertura é o elemento da edificação que recebe maior intensidade de radiação solar em edificações horizontais.

As chamadas coberturas verdes (com vegetação) podem constituir alternativas viáveis para minimizar as altas temperaturas do interior das edificações, provocadas pela radiação solar excessiva, além de auxiliar as cidades a controlar inundações (absorvendo uma parte da água pluvial), melhorar a qualidade do ar, prolongar a durabilidade da cobertura e reduzir custos de energia.

Pouey, Sattler e Schneider (1998), monitoraram o desempenho térmico de uma cobertura verde e de uma tipo terraço (laje exposta), na cidade de Pelotas, RS, durante períodos de verão e inverno. Os resultados mostraram que, em termos de temperaturas superficiais, a externa registrou menor amplitude de variação, tanto no inverno quanto no verão e, a interna, foi menor no verão e praticamente igual à do terraço no inverno. Quanto às temperaturas do ar interno, as da cobertura verde foram sempre menores no verão, e no inverno, tornaram-se iguais ou superiores às temperaturas internas do terraço. Portanto, a cobertura verde apresentou melhores respostas.

Morais e Roriz (2003), realizaram uma pesquisa em São Carlos, SP, na qual mediram as temperaturas internas em dois tipos de guaritas de edifícios: uma com laje comum e outra com laje ajardinada. Após os resultados, concluiu-se que ao longo do dia, as temperaturas superficiais da laje comum acumulam 65,2 graus-hora de calor acima das temperaturas do ar, enquanto a cobertura verde acumula menos de $40 \%$ deste valor. Além deste aspecto, nos horários mais quentes do dia a cobertura verde contribui para a refrigeração do ambiente, pois sua temperatura superficial permanece abaixo da temperatura do ar desde as 9 até as 18 horas. A maior diferença, $3,3^{\circ} \mathrm{C}$, acontece ao meio-dia, quando a temperatura superficial fica em $23,0^{\circ} \mathrm{C}$ e a temperatura do ar chega a $26,3 \stackrel{\circ}{\circ} \mathrm{C}$.

Lichtenberg e Barroso-Krause (2005), desenvolveram em seu projeto Ecohouse, utilizando uma residência localizada no Rio de Janeiro como célula-teste, as lajes verdes, as 


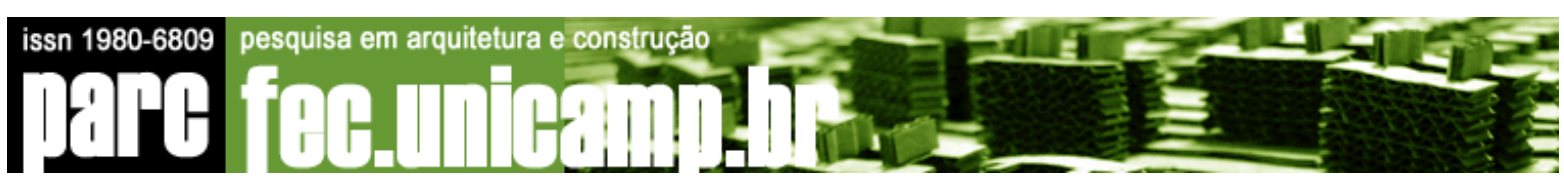

quais são formadas por grama esmeralda, capim limão, algumas ervas, uma pitangueira e hibiscos. Após dois verões, a laje já se encontra totalmente estabilizada e pôde ser constatado pelos ocupantes a sensação de conforto térmico proporcionado pela sua implementação - não só para o ambiente interno abaixo da laje - mas também quando de seu uso e para os vizinhos que não recebem mais o calor refletido pelo antigo telhado de telhas francesas.

Vecchia (2005), verificou que uma CVL (cobertura verde leve) instalada no campus da USP em São Carlos atinge uma temperatura superficial interna máxima de $26,7^{\circ} \mathrm{C}$, ficando inclusive abaixo da temperatura máxima do ar registrada que foi de $28,8^{\circ} \mathrm{C}$. Fato que significa que as superfícies interiores das CVLs contribuem para a absorção do calor interno, no período crítico que ocorre na parte da tarde.

Cabe ainda frisar que o valor máximo encontrado para a temperatura do ar interior do sistema CVL ainda se manteve baixo, porém não no momento de pico da temperatura externa ( $34^{\circ} \mathrm{C}$ às 14 horas e 30 minutos) e sim às 19 horas com um valor de $28,8^{\circ} \mathrm{C}$. Isto é, com um atraso de aproximadamente 5 horas. No mesmo horário, a comparação se traduz da seguinte forma: temperatura externa igual a $34^{\circ} \mathrm{C}$ contra $26^{\circ} \mathrm{C}$ da temperatura interna da $\mathrm{CVL}$, ou seja, um amortecimento de $8^{\circ} \mathrm{C}$. O que é bastante aceitável para o comportamento térmico, nesse dia experimental de excepcional calor, que se apresentou com valores acima da média das máximas, para esse episódio climático de transição primavera-verão, na região de São Carlos (SP).

\section{OBJETIVO}

Esta pesquisa tem como objetivo geral avaliar o comportamento térmico de uma cobertura verde com a grama Brachiaria humidicola (grama Braquiária) e verificar as diferenças entre as temperaturas da laje com essa grama e com a grama Esmeralda.

\section{MÉTODO}

A cobertura verde analisada é formada pelos seguintes componentes (Figura 1): 

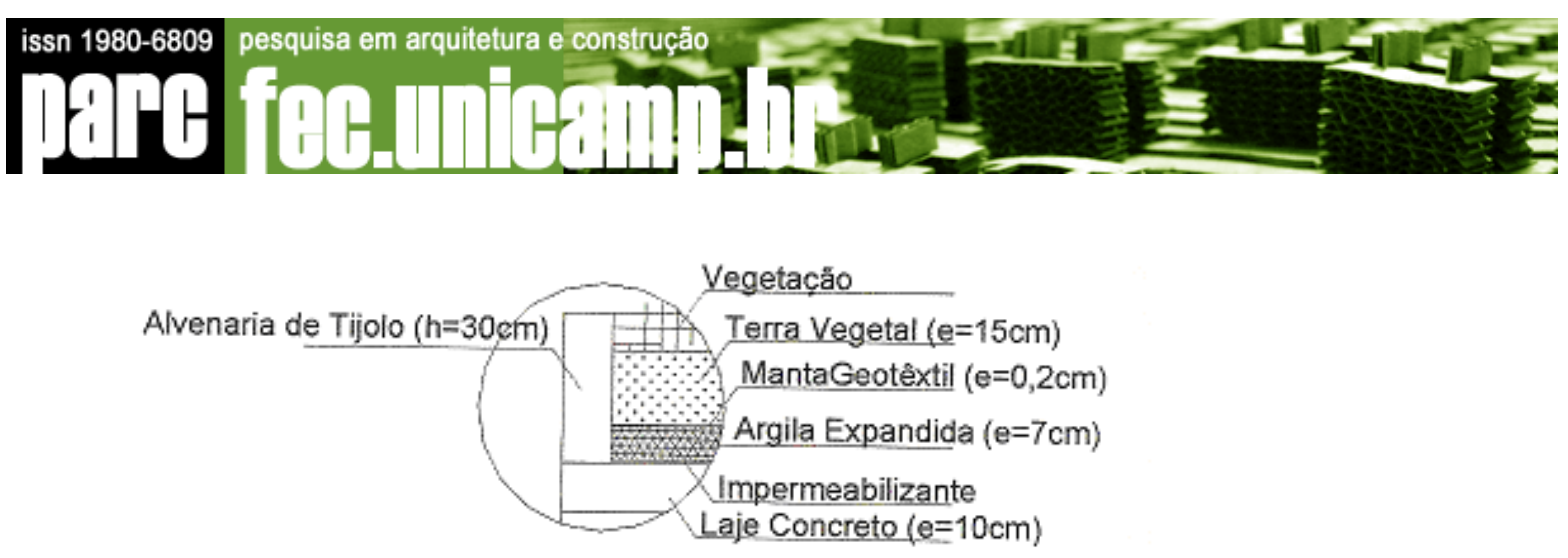

Figura 1 - Camadas componentes da cobertura verde analisada

\subsection{As Células-Teste: laje tradicional e cobertura verde}

As células-teste foram construídas sobre a laje de uma edificação existente no Departamento de Ecologia e Biologia Evolutiva da UFSCar, campus da cidade de São Carlos, região central do Estado de São Paulo.

O clima da região é o tropical de altitude, que, segundo a classificação de Köeppen, é o Cwa, clima quente com inverno seco, no qual a temperatura média do mês mais frio é inferior a $18^{\circ} \mathrm{C}$ e a do mês mais quente, ultrapassa $22^{\circ} \mathrm{C}$, com verões chuvosos e invernos secos, caracterizando seis meses quentes e úmidos e seis meses frios e secos (EMBRAPA, 2008). A precipitação pluviométrica anual é em média de 1500mm (PEREZ JÚNIOR, 2008).
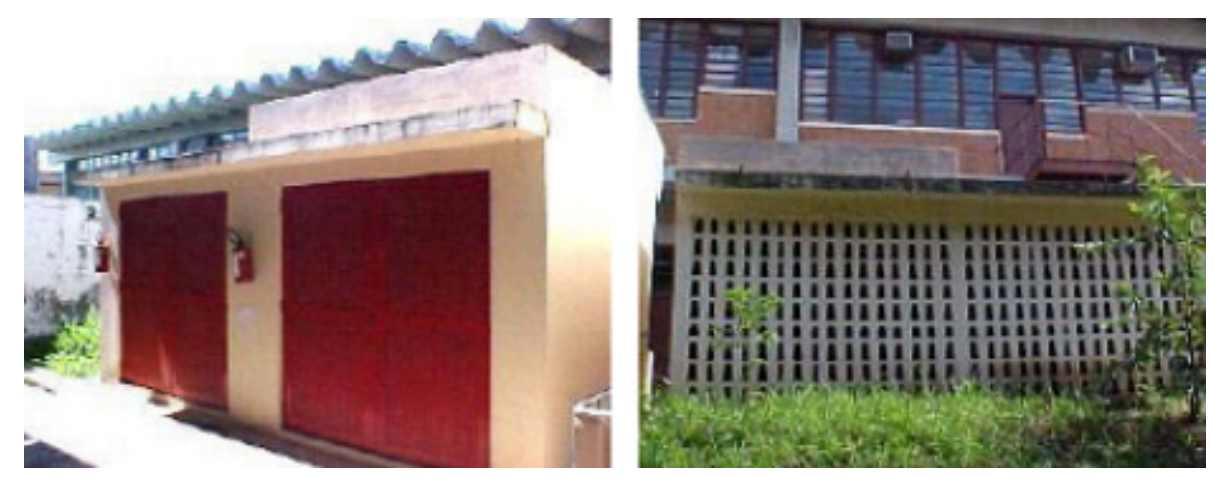

Figura 2 - Panorama da edificação onde está implantada a cobertura verde
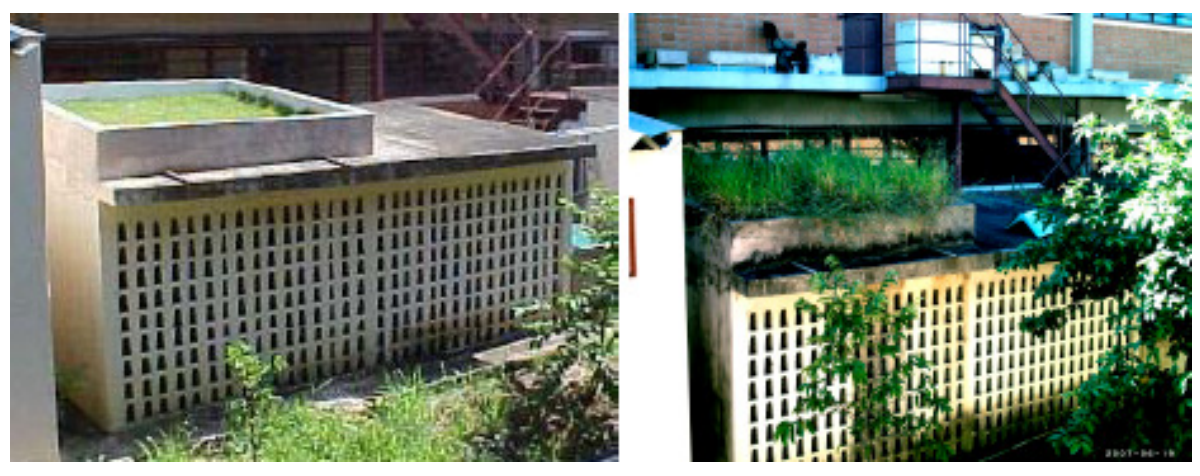


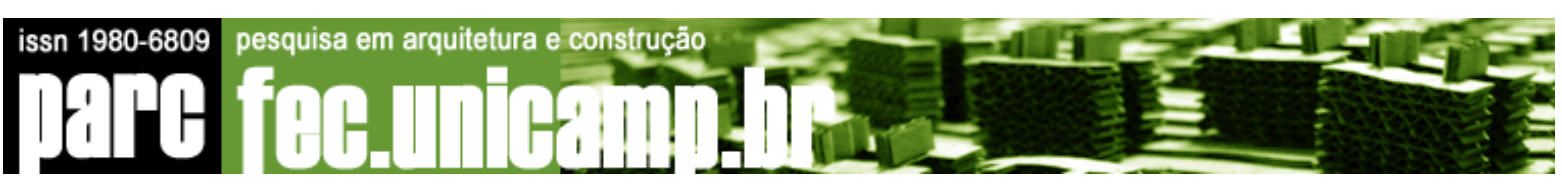

Figura 3 - Panorama dos canteiros com as gramas Esmeralda (esquerda) e Braquiária (direita)

Essa edificação possui dois ambientes, separados ao meio por uma parede. O sistema construtivo é composto de alvenaria de bloco cerâmico de 8 furos e revestida com argamassa sob pintura acrílica nas vedações verticais laterais e frontal e lajes pré-moldadas de concreto com camada de regularização em argamassa, nas vedações horizontais. A vedação posterior é composta por elementos vazados em toda sua extensão (Figura 2).

$\mathrm{Na}$ célula-teste com cobertura verde foi realizada recentemente uma pesquisa similar com a grama Esmeralda, a qual foi substituída pela grama Braquiária (Figura 3).

Foi selecionada a espécie Braquiária porque esta obedece aos seguintes critérios:

\# planta resistente ao clima da cidade de São Carlos;

\# tamanho e desenvolvimento das raízes, não sendo aconselhável o uso de plantas com raízes que possam danificar a laje e o sistema de impermeabilização;

\# a parte aérea da planta de modo que não fosse produzido muito material orgânico que pudesse dificultar a drenagem;

\# tempo curto de crescimento da planta;

\# planta que não serve como habitat de animais perigosos (como, por exemplo, as bromélias, que possibilitariam a criação de larvas do mosquito Aedes aegypti);

\# planta com folhas de superfície grande - melhora a retenção da água, o sombreamento do substrato, diminui mais a temperatura do ambiente através da evaporação e da evapotranspiração e diminui o impacto das chuvas torrenciais, protegendo o substrato contra a erosão.

\subsection{Material Utilizado nos Monitoramentos}

Para monitorar as condições higrotérmicas ambientais, adotou-se um sistema eletrônico de aquisição de dados, constituído por registradores de temperatura e umidade relativa do ar e temperatura superficial, modelo $\mathrm{HOBO}^{\circledR}$, programáveis para intervalos de tempo pré-fixados.

De modo a evitar interferências que prejudicassem a identificação das variáveis medidas, os aparelhos foram posicionados estrategicamente à sombra e no interior de recipientes de alumínio, estes com pequenas aberturas que permitissem a livre circulação do ar.

As variáveis medidas foram as seguintes: 


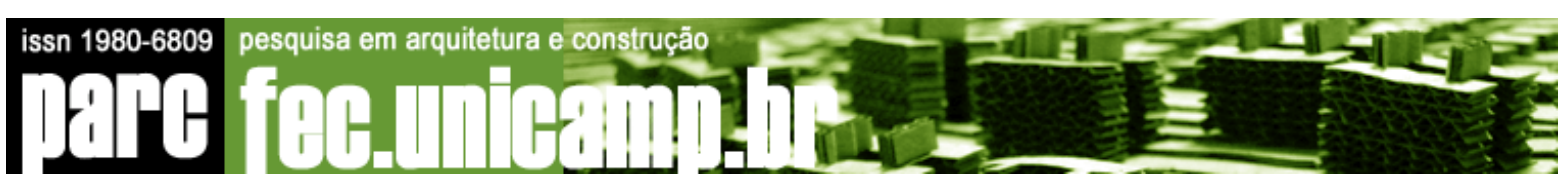

Tbs $\left({ }^{\circ} \mathrm{C}\right)$ : temperaturas do ar interno e externo a célula-teste;

TSI ( $\left.{ }^{\circ} \mathrm{C}\right)$ : temperatura superficial interna das lajes;

UR (\%): umidade relativa do ar.

Os dados de temperatura superficial interna das lajes foram obtidos mediante sensor externo desenvolvido para esse fim (conectado diretamente no $\mathrm{HOBO}^{\circledR}$ ), com ponta de aço inoxidável e à prova d'água. Para melhorar o contato e eliminar o ar entre o sensor e a laje, o mesmo teve sua ponta preenchida com pasta térmica e foi fixado na laje com fita adesiva e fio de nylon.

Os dados climáticos mensais, bem como os de radiação solar e de ventos, foram obtidos junto à estação climatológica da Escola de Engenharia de São Carlos - EESC e do Centro de Recursos Hídricos e Ecologia Aplicada - CRHEA / Universidade de São Paulo.

\subsection{Jardim 1.1 - Temperaturas Superficiais em Vegetação}

Os dados referentes às temperaturas superficiais externas das lajes foram estimados por intermédio do programa Jardim 1.1 - Temperaturas Superficiais em Vegetação (RORIZ, 2003), que adota um modelo de cálculo baseado no método de Penmain-Monteith, cuja equação determina a taxa de evapotranspiração da água em plantas e no solo. Com base no arquivo de dados, o programa calcula os valores das variáveis envolvidas e gera dois tipos de gráfico: um com as curvas de temperaturas do ar e superficiais externas nas duas coberturas e, outro, com as curvas de irradiações extraterrestre, global, de onda longa, líquida e energia de evaporação. As equações, melhor explicadas, e suas respectivas referências são apresentadas no próprio programa.

\subsection{Influência da Insolação}

Durante a fase de desenvolvimento da grama, observou-se que em certos locais no canteiro, a vegetação apresentava um maior crescimento. Isso se deve à desigualdade de distribuição de luz sobre o canteiro, pois a presença de edificações ao redor do mesmo faz com que haja um sombreamento em determinados locais e horários ao longo do dia (Figura 4). 

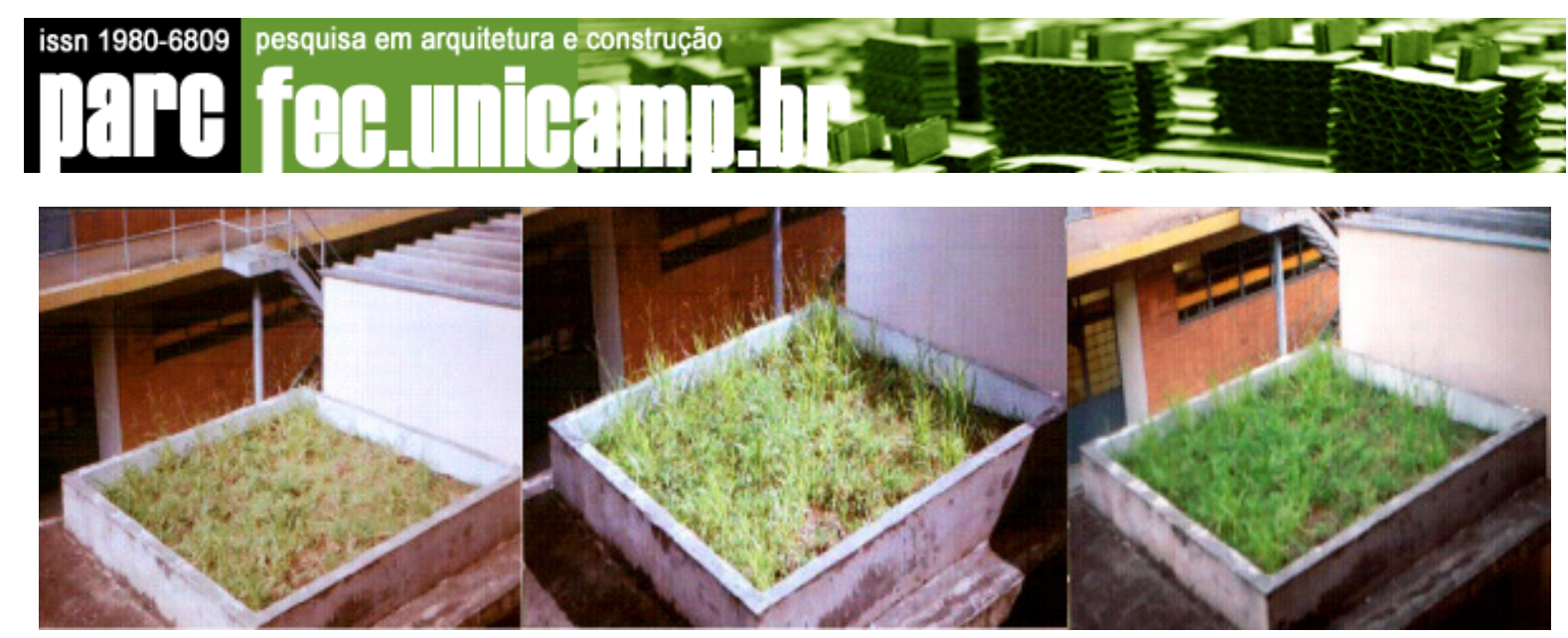

Figura 4 - Posições do sol pela manhã, início e fim de tarde

\subsection{Medições}

Após o treinamento no uso e instalação dos aparelhos registradores, as medições foram iniciadas. Conforme mostra a tabela 1, realizaram-se duas medições no período de frio e duas no de calor para aumentar a base de dados e assim confirmar o comportamento da cobertura verde nessas situações.

Tabela 1 - Períodos em que foram realizadas as medições

\begin{tabular}{|l|c|}
\hline \multicolumn{2}{|c|}{ Medições } \\
\hline Período de frio & 14 a 23 de junho de 2006 \\
\cline { 2 - 2 } & 25 de julho a 07 de agosto de 2006 \\
\hline Período de calor & 17 a 26 de novembro de 2006 \\
\cline { 2 - 2 } & 16 a 29 de março de 2007 \\
\hline
\end{tabular}

\section{ANÁLISE DE RESULTADOS}

A fim de obter dados relativos à evolução térmica das lajes, os aparelhos registradores foram programados para realizar varreduras de temperatura do ar interno e externo à edificação, umidade relativa do ar e temperatura superficial interna das lajes, a cada 15 minutos, 24 horas por dia.

Para obtenção dos dados internos à edificação, as variáveis ambientais foram medidas em um ponto de cada cobertura. Os aparelhos foram instalados em dois conjuntos formados, cada um deles, por um registrador de temperatura e umidade relativa do ar, inserido num recipiente de alumínio, e de temperatura superficial, obtida com o cabo sensor instalado nas faces internas das lajes, a $80 \mathrm{~cm}$ da parede com elemento vazado, onde a incidência solar sobre a grama predomina durante todo o dia. Os dados externos de 


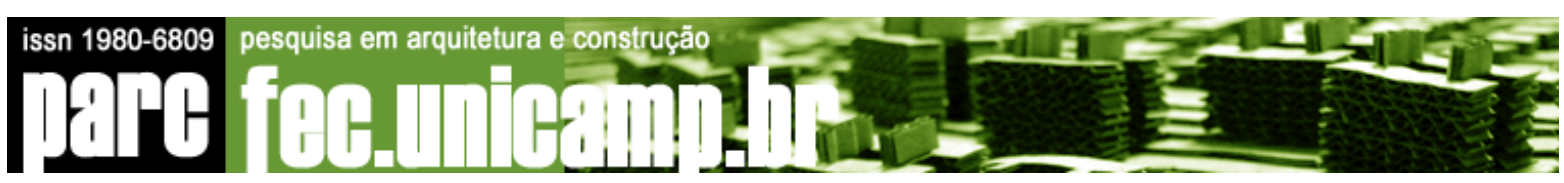

temperatura e umidade relativa do ar foram obtidos a partir de um aparelho, inserido em um recipiente de alumínio, instalado no edifício à frente da célula-teste.

Após as medições, os valores registrados pelos aparelhos foram adaptados para hora solar, calculando-se a média desses valores para cada hora, obtendo-se assim o dia médio.

Devido à grande área de aberturas (elementos vazados), não foram significativas as diferenças entre temperaturas do ar externo e do ar interno dos dois ambientes nas duas primeiras medições (Figuras 5 e 8). Já a terceira e quarta medições indicaram expressivas diferenças (Figuras 11 e 14).

\subsection{Medição em Junho de 2006}

Durante esse período não houve chuva e o céu esteve sempre claro. A temperatura superficial interna da laje tradicional apresentou maiores oscilações diárias, com máxima de $20.2^{\circ} \mathrm{C}$, enquanto que a da cobertura verde foi de $17.8^{\circ} \mathrm{C}$. As amplitudes médias, de $7.1^{\circ} \mathrm{C}$ e de $2.7^{\circ} \mathrm{C}$, da laje tradicional e cobertura verde, respectivamente, evidenciaram o melhor desempenho da cobertura verde (Figura 6).

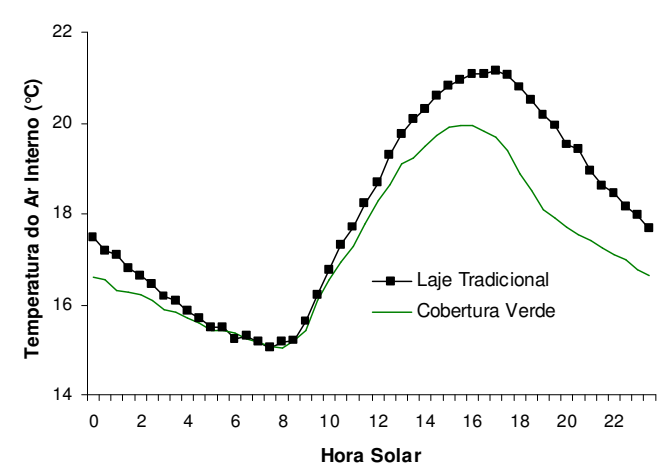

Figura 5 - Temperatura Interna do $\mathrm{Ar}$ Dia Médio do período 14 a 23/06/06

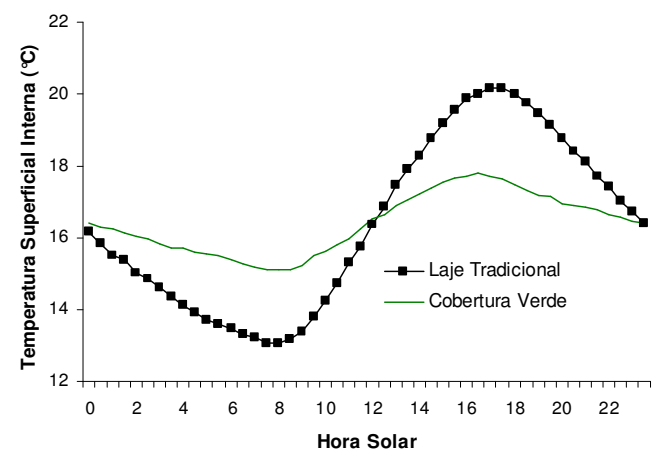

Figura 6 - Temperatura Superficial Interna Dia Médio do período 14 a 23/06/06 


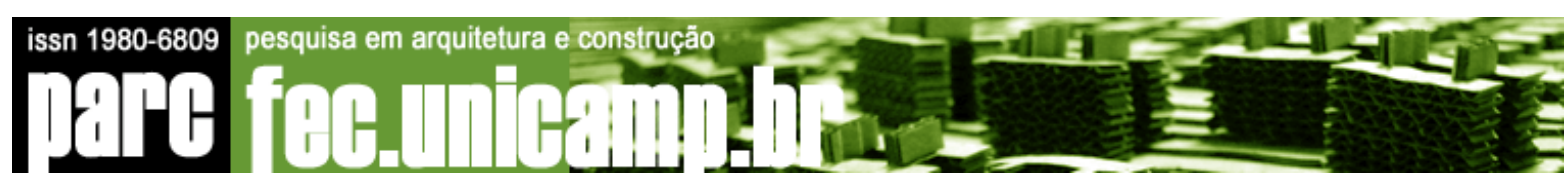

Comparada com a temperatura superficial externa da laje tradicional, a temperatura superficial externa da cobertura verde sofreu variações térmicas muito menores. A maior diferença entre elas foi de $20.5{ }^{\circ} \mathrm{C}$ (Figura 7).

Percebe-se pelo gráfico ao lado que 0 período medido foi menor que os dois anteriores, pelo motivo de falta de dados de radiação solar fornecidos pelo CRHEA, os quais são necessários para a obtenção dessa temperatura

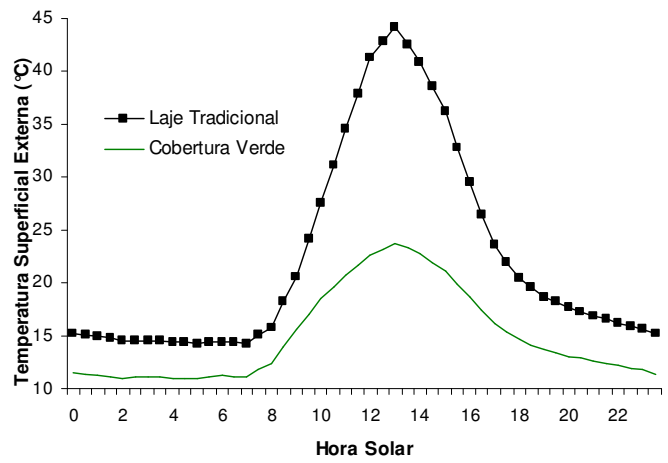

Figura 7 - Temperatura Superficial Externa Dia Médio do período 18 a 23/06/06 que é estimada pelo programa Jardim1.1 descrito anteriormente.

\subsection{Medição em Julho/Agosto de 2006}

Nesse período houve chuva e céu nublado entre 29 de julho e 02 de agosto. Assim como já era esperado, a temperatura superficial interna da laje tradicional apresentou maiores oscilações diárias, com máxima de $22.2^{\circ} \mathrm{C}$, enquanto que a da cobertura verde foi de $19.2^{\circ} \mathrm{C}$. As amplitudes médias, de $7.8^{\circ} \mathrm{C}$ e de $2.7^{\circ} \mathrm{C}$, da laje tradicional e cobertura verde, respectivamente, evidenciaram o melhor desempenho da cobertura verde (Figura 9).

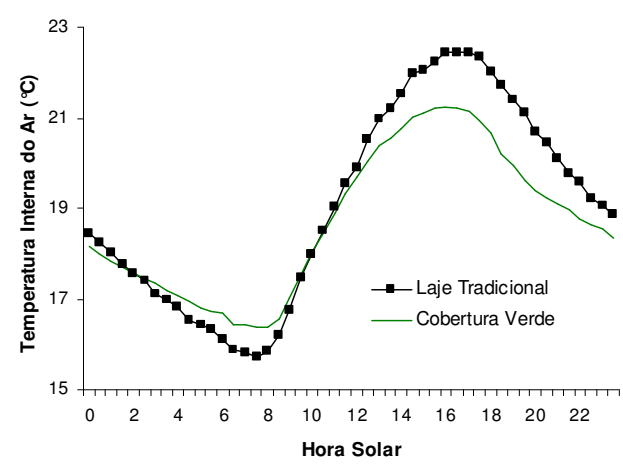

Figura 8 - Temperatura Interna do $\mathrm{Ar}$ Dia Médio do período 25/07 a 07/08/06

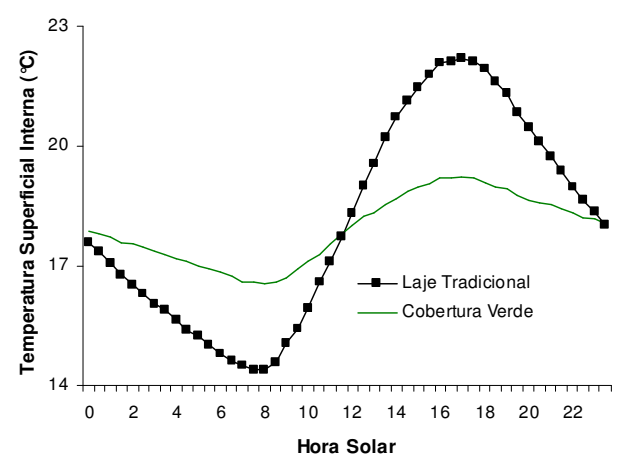

Figura 9 - Temperatura Superficial Interna Dia Médio do período 25/07 a 07/08/06 


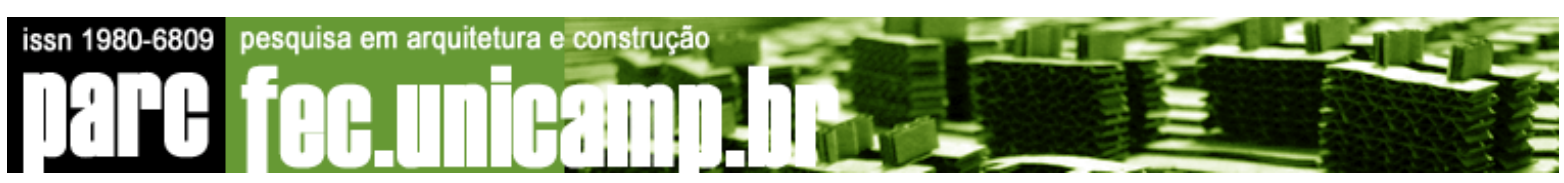

A temperatura superficial externa da laje tradicional apresenta uma amplitude bem maior quando comparada com a temperatura superficial externa da cobertura verde, com uma diferença de até $18.3^{\circ} \mathrm{C}$ entre elas (Figura 10 ).

Por falta de dados de radiação solar fornecidos pelo CRHEA, a temperatura superficial externa para essa medição, foi estimada, através do programa Jardim 1.1, para um período menor que as temperaturas anteriores.

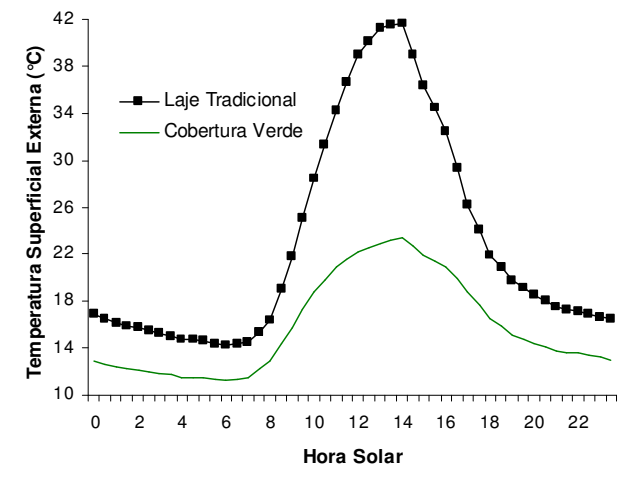

Figura 10 - Temperatura Superficial Externa Dia Médio do período 25 a 30//07/06

\subsection{Medição em Novembro de 2006}

Nesta medição chuva e céu nublado estiveram presentes entre os dias 20 e 22, e as temperaturas registradas são maiores que nas outras duas medições, fato observado pela temperatura superficial interna da laje tradicional, que apresentou maiores oscilações diárias, com máxima de $41.6^{\circ} \mathrm{C}$, enquanto que a da cobertura verde foi de $26.2^{\circ} \mathrm{C}$. As amplitudes médias, de $19.7^{\circ} \mathrm{C}$ e de $2.6^{\circ} \mathrm{C}$, da laje tradicional e cobertura verde, respectivamente, evidenciaram o melhor desempenho da cobertura verde (Figura 12).

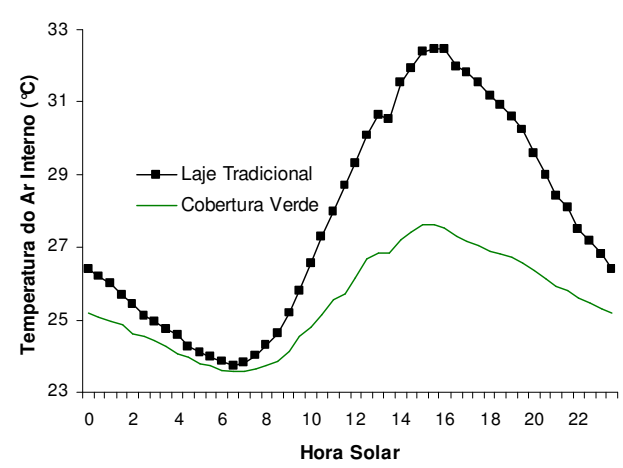

Figura 11 - Temperatura Interna do Ar Dia Médio do período 17 a 26/11/06

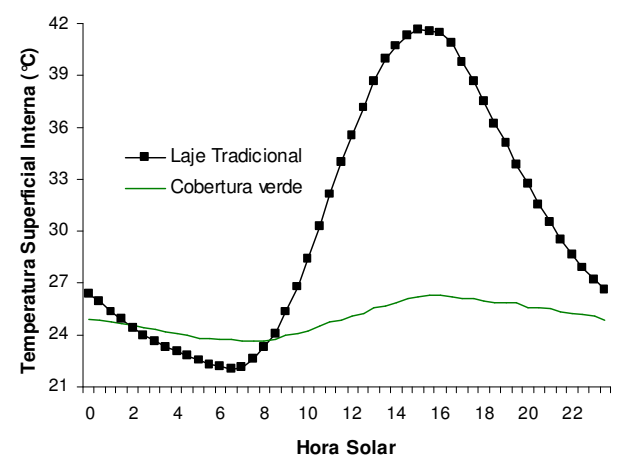

Figura 12 - Temperatura Superficial Interna Dia Médio do período 17 a 26/11/06 


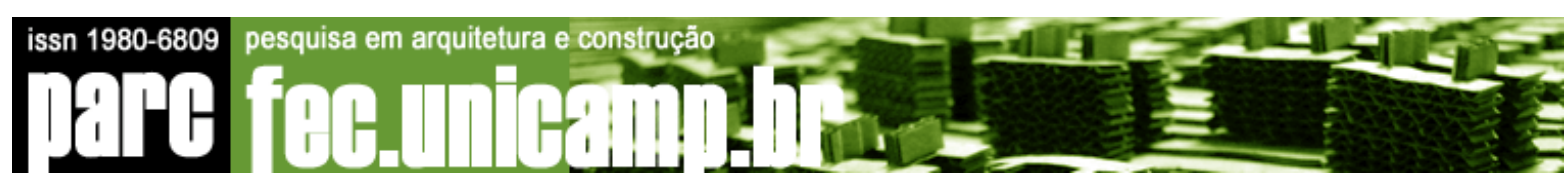

Percebe-se que a temperatura superficial externa da cobertura verde sofreu variações térmicas muito menores quando comparada com a temperatura superficial externa da laje tradicional, sendo a maior diferença entre elas de $29.8^{\circ} \mathrm{C}$ (Figura 13).

Novamente, a temperatura superficial externa foi estimada pelo programa Jardim 1.1, e num período menor que as outras temperaturas desta medição, pela falta de dados de radiação solar fornecidos pelo CRHEA.

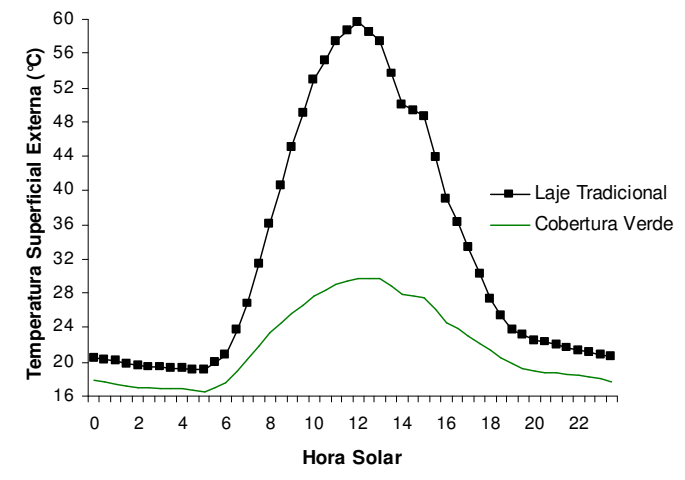

Figura 13 - Temperatura Superficial Externa Dia Médio do período 17 a 23/11/06

\subsection{Medição em Março de 2007}

Houve chuva e céu nublado entre os dias 16 e 21. Esta medição mostra também que as temperaturas registradas são maiores que nas duas primeiras medições, fato observado pela temperatura superficial interna da laje tradicional, que apresentou maiores oscilações diárias, com máxima de $40.1^{\circ} \mathrm{C}$, enquanto que a da cobertura verde foi de $23.2^{\circ} \mathrm{C}$. As amplitudes médias, de $19.4^{\circ} \mathrm{C}$ e de $1.1^{\circ} \mathrm{C}$, da laje tradicional e cobertura verde, respectivamente, evidenciaram o melhor desempenho da cobertura verde (Figura 15).

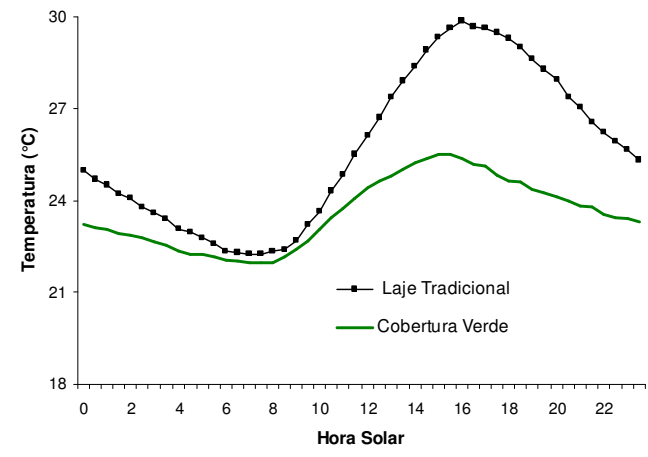

Figura 14 - Temperatura Interna do Ar Dia Médio do período 16 a 29/03/07

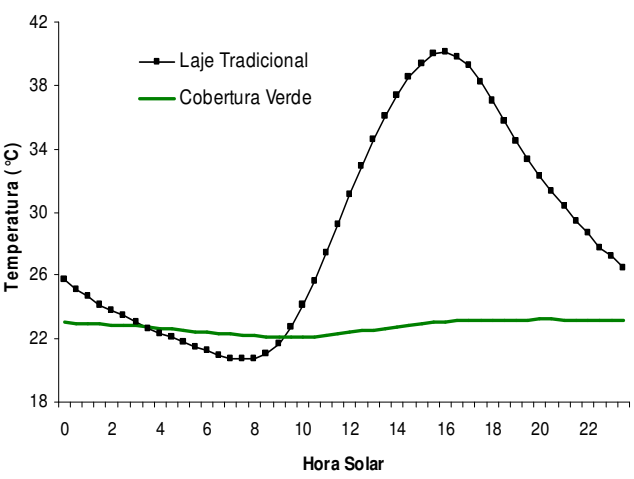

Figura 15 - Temperatura Superficial Interna Dia Médio do período 16 a 29/03/07 


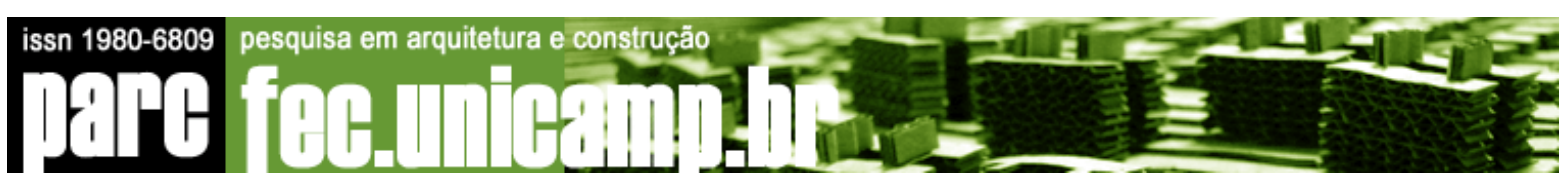

Nota-se que a temperatura superficial externa da cobertura verde sofreu variações térmicas muito menores quando comparada com a temperatura superficial externa da laje tradicional, sendo a maior diferença entre elas de $28.5^{\circ} \mathrm{C}$ (Figura 16).

A temperatura superficial externa foi estimada pelo programa Jardim 1.1, e no mesmo período que as outras temperaturas desta medição, pois desta não houve falta de dados de radiação solar fornecidos pelo CRHEA.

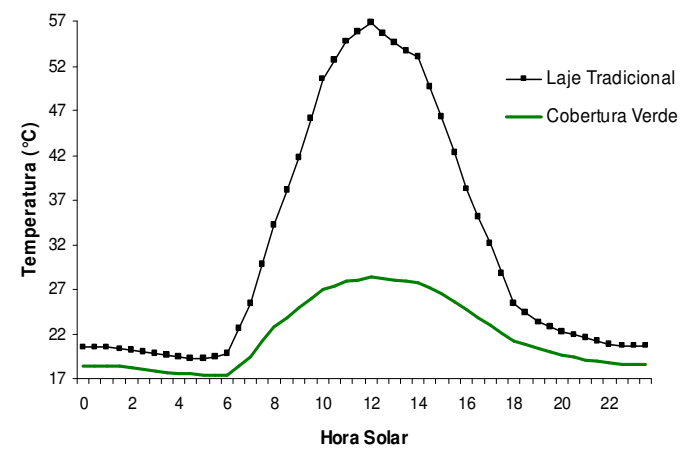

Figura 16 - Temperatura Superficial Externa Dia Médio do período 16 a 29/03/07

\subsection{Comparações entre os comportamentos das duas gramas}

Para comparar o comportamento térmico entre as duas gramas foram utilizados os dados dos dias médios da pesquisa anterior (MORAIS, 2004), para a grama Esmeralda, e a média dos dias médios para grama Braquiária, pelo fato desta possuir duas medições para cada situação de frio e calor, enquanto Morais (2004) realizou uma medição para cada situação. Os gráficos das temperaturas do ar interno não foram considerados pelo fato da edificação possuir uma parede com blocos vazados e nem das superficiais externas por falta de dados suficientes no caso da grama Esmeralda.

\subsubsection{Medições realizadas no período frio}

A figura 17 apresenta as comparações das medições realizadas neste período para as duas gramas. Nota-se que a temperatura superficial interna variou $2.7^{\circ} \mathrm{C}$ entre as máximas com a grama Braquiária e $2.4^{\circ} \mathrm{C}$ com a grama Esmeralda, em relação à laje tradicional. Neste caso, percebe-se que houve uma semelhança entre o comportamento térmico das duas gramas.
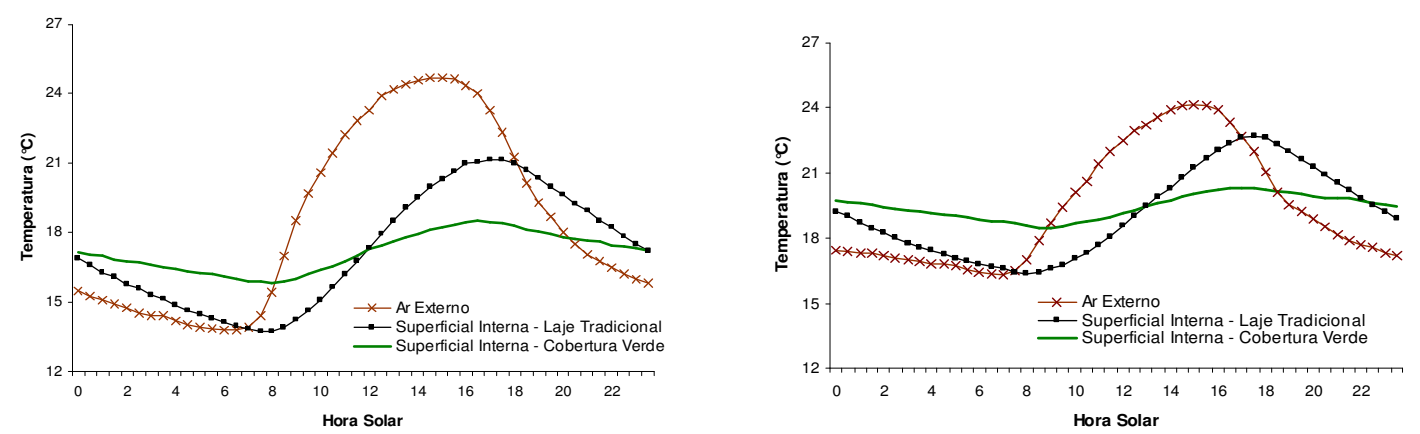


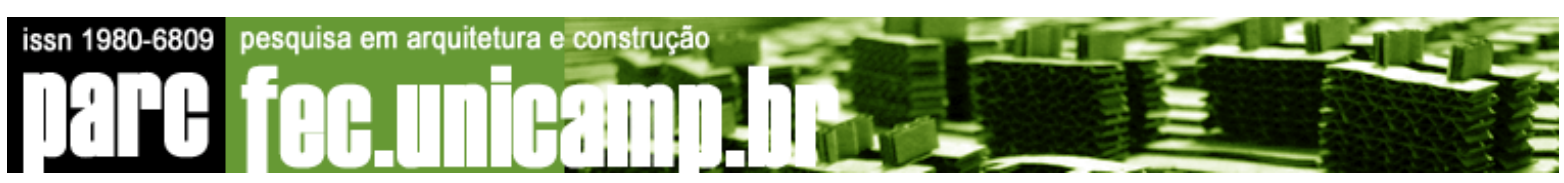

Temperatura Superficial Interna: média entre os períodos de 14 a 23/06/2006 e de $25 / 07$ a 07/08/2006
Temperatura Superficial Interna no período de 05 a 12/06/2003.

Figura 17 - Dia Médio: comparação entre as temperaturas superficiais internas da laje tradicional e cobertura verde registradas durante a medição no período de frio com a grama Braquiária (esquerda) e a grama Esmeralda (direita)

\subsubsection{Medições realizadas no período calor}

A figura 18 representa as comparações das medições realizadas neste período para as duas gramas.

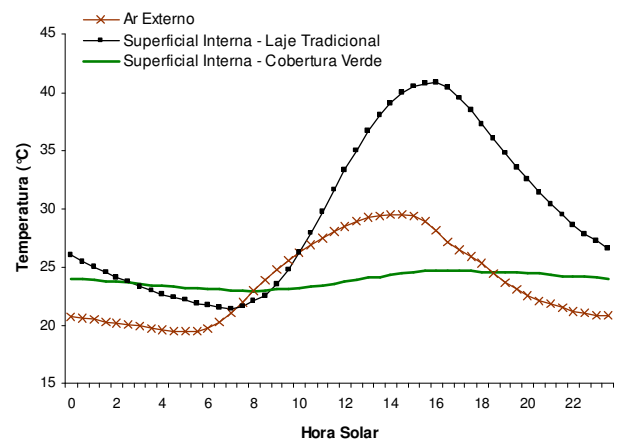

Temperatura Superficial Interna: média entre os períodos de 17 a 26/11/2006 e de 16 a 29/03/2007

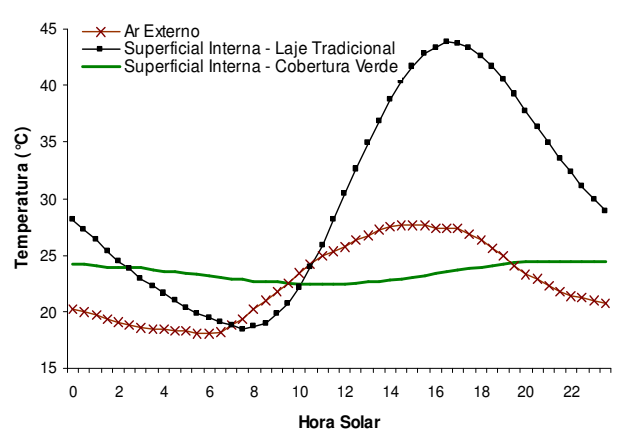

Temperatura Superficial Interna no período de 15 a 22/10/2003. Fonte: Morais, 2004

Figura 18 - Dia Médio: comparação entre as temperaturas superficiais internas da laje tradicional e cobertura verde registradas durante a medição no período de calor com a grama Braquiária (esquerda)

$$
\text { e a grama Esmeralda (direita) }
$$

Observa-se que a temperatura superficial interna do ambiente com grama Braquiária apresentou uma variação entre as máximas de $16.1^{\circ} \mathrm{C}$ e com a grama Esmeralda de $19.3^{\circ} \mathrm{C}$, em relação ao ambiente com a laje tradicional. Neste caso, percebe-se também, que houve uma semelhança entre o comportamento térmico das duas gramas.

\section{CONCLUSÕES}

Ao analisar-se as temperaturas internas na situação de calor, percebe-se que há uma contribuição significativa da cobertura verde, porque com a incidência do sol, a evapotranspiração do vegetal retira calor da cobertura, resfriando a superfície do teto.

\section{http://www.fog.unitamp.hr/ part}




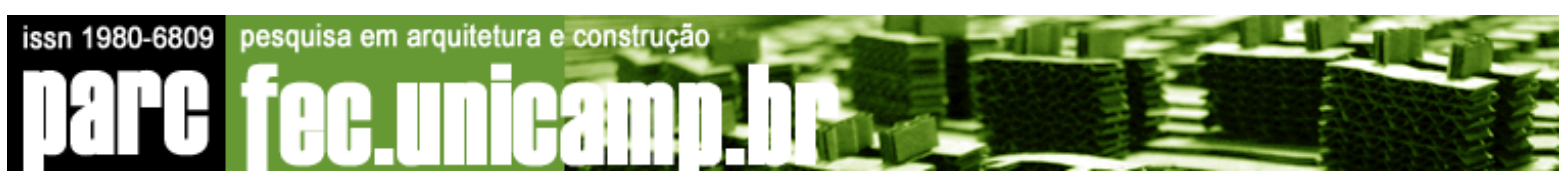

Quanto às temperaturas superficiais internas percebe-se que o melhor desempenho foi da cobertura verde, principalmente na situação de calor, no qual há uma diferença de até $16^{\circ} \mathrm{C}$ entre as duas coberturas, fato provocado pelo sombreamento, inércia e refrigeração evaporativa, proporcionados pela cobertura verde.

Nas temperaturas superficiais externas, a vegetação apresenta temperaturas bem menores que a laje tradicional, caso observado nas quatro medições e, justificado pela capacidade da vegetação de reduzir o ganho de calor por irradiância solar de ondas curtas, uma conseqüência do efeito de refrigeração evaporativa.

Comparando-se os resultados dos monitoramentos realizados com as duas gramas nos períodos de frio e de calor, percebe-se que, embora a grama Braquiária seja mais densa e, portanto, ofereça maior proteção para a laje de concreto, foi detectada uma semelhança entre seus comportamentos. Entretanto, não significa que o comportamento térmico das coberturas com grama Esmeralda e Braquiária são iguais, pois é necessário considerar o período de irrigação das duas gramas (a umidade da terra tem uma forte influência no processo de troca de calor), a velocidade do vento, e também por tratar-se de média entre valores no caso da grama Braquiária.

Observa-se que as duas lajes (tradicional e verde) se encontram sobre o mesmo edifício e, portanto, não há plena igualdade de condições, pois elas cobrem paredes de diferentes orientações e diferentes condições de sombreamento do edifício. $O$ ideal seria que as células-teste fossem dimensionalmente iguais e sujeitas às mesmas influências do entorno, e não adaptadas em edifício existente com suas idiossincrasias. Entretanto, desprezou-se esse detalhe pelo fato do objeto de estudo serem as coberturas e não as edificações.

No Brasil a dificuldade de difusão das coberturas verdes está na cultura e desconfiança do desempenho das mesmas. Analisa-se, também, a relação entre o custo e os benefícios dessas coberturas e percebem que o custo depende dos materiais que nelas são empregados, os quais têm influência na sua durabilidade. Embora a construção de uma cobertura ajardinada apresente um alto custo inicial, seus benefícios, como a economia de energia e a retenção de água pluvial, trarão um retorno financeiro positivo futuramente.

\section{REFERÊNCIAS BIBLIOGRÁFICAS}

EMPRESA BRASILEIRA DE PESQUISA AGROPECUÁRIA - EMBRAPA. Clima e hidrologia . Disponível em www.cppse.embrapa.br. Acesso em 09/11/2008.

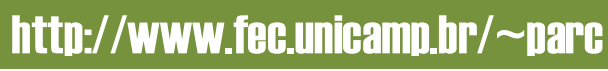




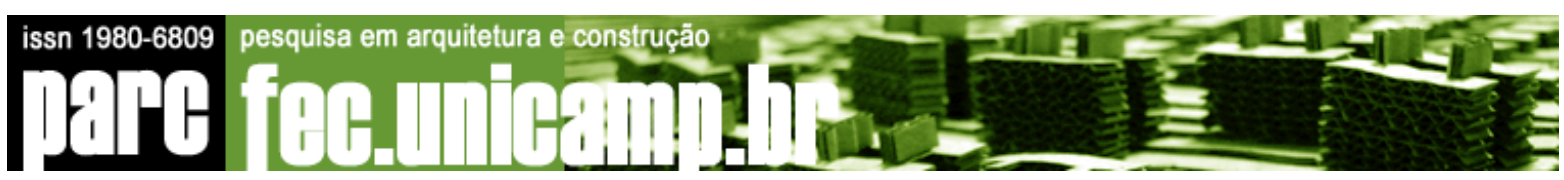

LICHTENBERG, R. A.; BARROSO-KRAUSE, C. Estratégias bioclimáticas aplicadas em edificação residencial - 0 projeto Ecohouse Urca. In: $8^{\circ}$ Encontro Nacional sobre Conforto no Ambiente Construído - ENCAC. Centro Cultural e de Exposições de Maceió/2005.

MORAIS, C.S.; RORIZ, M. Comparação entre os desempenhos térmicos de cobertura ajardinada e laje comum em guaritas. In: $7^{\circ}$ Encontro Nacional sobre Conforto no Ambiente Construído - ENCAC. PUC Curitiba/2003.

MORAIS, C.S. Desempenho térmico de coberturas vegetais em edificações na cidade de São Carlos. Dissertação de Mestrado. UFSCar. São Carlos / 2004.

PEREZ JÚNIOR, O. R. A cidade de São Carlos. Disponível em:

http://educar.sc.usp.br/biologia/textos/m a txt6.html. Acesso em : 09/11/2008.

POUEY, M. T. F.; SATTLER, M.A.; SCHNEIDER, P.S. Coberturas verdes: análise do desempenho térmico. In: $7^{\circ}$ Encontro Nacional de Tecnologia do Ambiente Construído - ENTAC, Núcleo de Pesquisa em Construção, Universidade Federal de Santa Catarina, Florianópolis/1998.

RORIZ, M. Jardim 1.1 - Temperaturas Superficiais em Vegetação. Versão 1.1. JARDIM.EXE. São Carlos, 2003. Aplicativo. 264KB.

VECCHIA, F. Cobertura verde leve (CVL): ensaio experimental. In: $8^{\circ}$ Encontro Nacional sobre Conforto no Ambiente Construído - ENCAC. Centro Cultural e de Exposições de Maceió/2005. 